\title{
Heart and Brain: Complex Relationships for Left Ventricular Dysfunction
}

\author{
Gianlorenzo Daniele $^{1} \cdot$ Stephanie DiLucia ${ }^{2} \cdot$ Pier-Giorgio Masci ${ }^{3} \cdot$ Federica del Monte ${ }^{1,4}$
}

Published online: 23 June 2020

(C) Springer Science+Business Media, LLC, part of Springer Nature 2020

\begin{abstract}
Purpose of Review This review summarizes the evidence for the established vascular/hypoperfusion model and explores the new hypothesis that configures the heart/brain axis as an organ system where similar pathogenic mechanisms exploit physiological and pathological changes.

Recent Findings Although associated by common risk factors, similar epidemiological stratification and common triggers (including inflammation, oxidative stress, and hypoxia), heart failure and Alzheimer's disease have been, for long time, viewed as pathogenically separate illnesses. The silos began to be broken down with the awareness that vascular dysfunction, and loss of cardiac perfusion pump power, trigger biochemical changes, contributing to the typical hallmark of Alzheimer's disease (AD) the accumulation of $\mathrm{A} \beta$ plaques and hyperphosphorylated Tau tangles. Compromised blood flow to the brain becomes the paradigm for the "heart-to-head" connection. Compelling evidence of common genetic variants, biochemical characteristics, and the accumulation of $\mathrm{A} \beta$ outside the brain suggests a common pathogenesis for heart failure (HF) and $\mathrm{AD}$. These new findings represent just the beginning of the understanding the complex connection between $\mathrm{AD}$ and HF requiring further studies and interdisciplinary approaches.

Summary Altogether, the current evidence briefly summarized in this review, highlight a closer and complex relationship between heart failure and Alzheimer's that goes beyond the vascular/perfusion hypothesis. Genetic and biochemical evidence begin to suggest common pathogenic mechanisms between the two diseases involving a systemic defect in the folding of protein or a seeding at distance of the misfolded proteins from one organ to the other.
\end{abstract}

Keywords Heart failure $\cdot$ Cardiomyopathy $\cdot$ Alzheimer's disease $\cdot A \beta \cdot$ Vascular dementia $\cdot$ Protein folding

\section{Introduction}

Heart failure (HF) and Alzheimer's disease (AD) are growing age-dependent diseases worldwide and major health threats in

Gianlorenzo Daniele and Stephanie DiLucia contributed equally to this work.

This article is part of the Topical Collection on Myocardial Disease

Federica del Monte

delmonte@musc.edu; federica.delmonte2@unibo.it

Gianlorenzo Daniele

daniele@musc.edu

Stephanie DiLucia

dilucia@musc.edu

Pier-Giorgio Masci

pier_giorgio.masci@kcl.ac.uk terms of morbidity, mortality, quality of life and health care costs. There are more than 5 million individuals suffering from HF in the USA and 60 million worldwide [1] with an aging prevalence growth of 4 to $9 \%$ from age 60 to 80 . The 
Table 1 Summary of the key findings reported in this review

\begin{tabular}{|c|c|c|c|}
\hline Disease determinant & Notable feature & Key findings & Ref \\
\hline \multirow[t]{5}{*}{ Reduced cerebral perfusion } & \multirow[t]{2}{*}{ Oxidative stress } & $\begin{array}{l}\text { - Hypoxia-induced cellular respiration exhaustion and increased } \\
\text { ROS production, promoting cell, and BBB injury }\end{array}$ & {$[21-23]$} \\
\hline & & - Worsened by $\mathrm{A} \beta$ build-up and consequent mitochondrial dysfunction & {$[24-26]$} \\
\hline & \multirow[t]{2}{*}{$\mathrm{A} \beta$ accumulation } & $\begin{array}{l}\text { - Reduced } \mathrm{A} \beta \text { clearance via } \mathrm{BBB} \text {, interstitial bulk flow, and/or } \\
\text { meningeal lymphatic impairment }\end{array}$ & {$[27,28]$} \\
\hline & & $\begin{array}{l}\text { - Reduced } \mathrm{A} \beta \text { clearance via } \mathrm{BBB} \text {, interstitial bulk flow, and/or } \\
\text { meningeal lymphatic impairment }\end{array}$ & [29-33] \\
\hline & Inflammation & $\begin{array}{l}\text { - Reduced microglial presence and functioning around } A \beta \text { plaques, } \\
\text { impairing } A \beta \text { internalization and clearance }\end{array}$ & {$[34]$} \\
\hline \multirow[t]{3}{*}{ Cardiovascular changes } & \multirow[t]{2}{*}{ Diastolic dysfunction } & $\begin{array}{l}\text { - Preserved EF accompanied by high filling pressures, weakened } \\
\text { myocardial contractility, reduced peripheral vasodilation, diminished } \\
\text { HR response, and less organ perfusion }\end{array}$ & {$[35-48]$} \\
\hline & & $\begin{array}{l}\text { - Retrospectively, HFpEF and LV hypertrophy were more likely to } \\
\text { be seen in AD patients }\end{array}$ & {$[6]$} \\
\hline & $\begin{array}{l}\text { Arterial stiffness, increased } \\
\text { central pulsatility }\end{array}$ & $\begin{array}{l}\text { - Associated with decreased peripheral BF, central A } \beta \text { accumulation, } \\
\text { BBB injury, cerebrovascular compromise, and brain hypoperfusion }\end{array}$ & [49-51] \\
\hline \multirow[t]{2}{*}{ Genetic variants } & \multirow[t]{2}{*}{ Presenilin (PSEN) -1 and -2} & - Same variants associated with both early-onset AD and sporadic iDCM & [4] \\
\hline & & - Promoter-specific variants have been observed in iDCM but not yet AD & [4] \\
\hline \multirow[t]{4}{*}{ Protein aggregation } & \multirow[t]{2}{*}{ Brain deposition } & - $\mathrm{AD}$ aggregates composed of $\mathrm{A} \beta$, tau, metal ions, and chaperones & {$[52]$} \\
\hline & & - Cofilin rods implicated in $\mathrm{AD}$ neuritis & [53] \\
\hline & \multirow[t]{2}{*}{ Heart deposition } & $\begin{array}{l}\text { - Aggregates have been identified in atrial fibrillation, cardiac amyloidosis, } \\
\text { and cardiomyopathies - notably, cofilin was isolated from iDCM aggregates }\end{array}$ & {$[4,6,54]$} \\
\hline & & - $\mathrm{A} \beta$ and $\mathrm{PAO}$ deposits seen in $\mathrm{AD}$ patients & {$[7 \cdot]$} \\
\hline \multirow[t]{5}{*}{ Systemic alterations } & \multirow[t]{2}{*}{ Peripheral $A \beta$ accumulation } & $\begin{array}{l}\text { - A } \beta \text { peripheral clearance impaired by decreased scavenger receptors, } \\
\text { less proteolytic enzymes, and liver/kidney malfunctioning }\end{array}$ & {$[55-58]$} \\
\hline & & $\begin{array}{l}\text { - } \mathrm{BBB} \text { damage promotes } \mathrm{A} \beta \text { release into the periphery and potential } \\
\text { seeding to other organs }\end{array}$ & {$[27,59]$} \\
\hline & Peripheral $A \beta$ Production & - Promotes central $\mathrm{A} \beta$ deposition and associated inflammation & {$[60-64]$} \\
\hline & \multirow[t]{2}{*}{ Exosome trafficking } & $\begin{array}{l}\text { - Help carry A } \beta \text { locally and systemically following A } \beta \text { endocytosis or } \\
\text { APP cleavage }\end{array}$ & {$[65-67]$} \\
\hline & & $\begin{array}{l}\text { - Bring MiR-1 from ischemic myocardium to hippocampus, inducing } \\
\text { microtubule damage }\end{array}$ & {$[68 \bullet]$} \\
\hline
\end{tabular}

prevalence of symptomatic HF in individuals over 65 years of age is estimated to be $6-10 \%$. Likewise, according to the World and Alzheimer's Association's Alzheimer's Reports, there are over 5 million cases of dementia in the USA, and 35 million worldwide [2]. One in nine people older than 65 years has AD [3]. By 2050, the number of cases of AD in age $>65$ may nearly triple, reaching as high as 16 million. Thus, if individually alone, HF and AD are modern plagues, recognizing their coexistence in the same patient $[4-6,7 \cdot]$ is an alarming prospective as people are living longer.

Epidemiological evidence indicates that HF also shares similar profiles in term of prevalence, age distribution, and high mortality $[8,9]$ with neurodegenerative processes including AD. Notably, HF represents, per se, a risk factor for developing dementia and AD [10].

In addition to these independent associative observations, over the past years it became increasingly evident that AD pathogenesis involves tissues and organs beyond the brain. Thus, in addition to the traditional view linking CVD and $A D$ via vascular, microvascular, and perfusion defects, clinical and experimental evidence join HF and AD though analogous biochemical characteristics and genetic profiles inferring the new hypothesis of a systemic (or metastatic) entanglement of the disease [4-6, 7•, 11-15].

While current estimates of the prevalence of dementia in $\mathrm{HF}$ are computed between 30 and $80 \%$ of patients [16-19], since its first discovery $[4-6,7 \bullet]$ initial reports provide a frightful estimate that HF occurs in a third of cases of $\mathrm{AD}$ accounting for over 20 million people affected worldwide [20].

Here, we will review the established knowledge and the latest insights on the link between heart and brain dysfunction through the lens of a systemic disorder or a communication between two of the body vital organs (summarized in Table 1).

\section{The Traditional View of "Cardiogenic Dementia"}

Since over four decades ago, cognitive dysfunction has been known to occur in patients with CVD, from which the term 
"cardiogenic dementia" was coined [69]. Yet, to the recent days, besides some neurological diseases such as the frontotemporal dementia with Parkinsonism adjoining two neurodegenerative phenotypes, $\mathrm{AD}$ is typically viewed, and addressed, as unique disease limited to the target organ or, at early stages, even restricted to specific brain regions.

Instead, there is a significant evidence, built over many years, indicating that more complex mechanisms are involved in AD and CVD altogether. Those, however, have mostly been considered as revolving around vascular dysfunction and brain hypoperfusion. Clinical studies have linked CVD, dementing processes, and $\mathrm{AD}$ through common triggers, including inflammation, oxidative stress, and hypoxia [70, 71], which are also common features in both neurodegenerative diseases and HF separately (Fig. 1).

\section{The Vascular Hypothesis}

A growing body of evidence has supported the role of blood perfusion in the pathogenesis of AD [72-74]. The current paradigm is that compromised blood flow to the brain is a major determinant for the "heart-to-head" connection [75-77]. Cognitive decline from impaired blood flow to the brain is shown early in pre-symptomatic $\mathrm{AD}$, while increasing blood flow to the brain improves AD symptoms [75]. Therefore, the vascular hypothesis had prevailed $[78,79]$ and, at times, risen over the original amyloid hypothesis [34, 80, 81].

Because the brain is a highly metabolically active organ that receives about $20 \%$ of cardiac output, it is subject to hypoxia induced by reduced blood flow [20, 15]. Tight regulations exist in order to maintain adequate blood flow and, consequently, oxygen delivery. Any insult to these mechanisms, therefore, confers a unique susceptibility to impaired perfusion [82]. Conditions that disrupt blood flow include structural changes as induced by atherosclerosis, or functional changes due to hypertension or cardiovascular dysfunction and HF. These have been shown to be significant risk factors for the development of dementia, independent of amyloid deposition and aging (Rev in [83]) [74].

To be noted, although vascular dementia is linked to reduced brain perfusion and often coexists with other dementia such as $\mathrm{AD}$, the vascular hypoperfusion hypothesis of $\mathrm{AD}$ is different from vascular dementia. Vascular dementia (not discussed here) is a condition due to any disorder that causes damages to the vessels (documented at imaging), such as stroke that can also lead to mild cognitive impairment and dementia [72].

\section{The Vascular Hypothesis-Structural Damage, Oxidative Stress, and Inflammation}

The cornerstone of the $\mathrm{AD}$ vascular hypothesis centers on the hypoxia, oxidative stress, and neurovascular unit (NVU) injury induced by reduced blood flow. Notably, the mixture of neural, glial, and other non-neuronal cells comprising the NVU helps regulating blood flow and maintain the integrity of the vasculature surrounding the brain $[84,85]$.

In response to this damage and disrupted perfusion, cellular respiration capabilities are quickly exhausted, and ATP is consumed without compensatory regeneration [22]. Reactive oxygen species (ROS) are produced [23], ion gradients become disrupted, and the resulting increase in intracellular calcium triggers cellular catabolism [21]. Damage to the endothelial cells, the main sentry of the blood brain barrier (BBB), will increase its permeability. Under normal physiologic conditions,

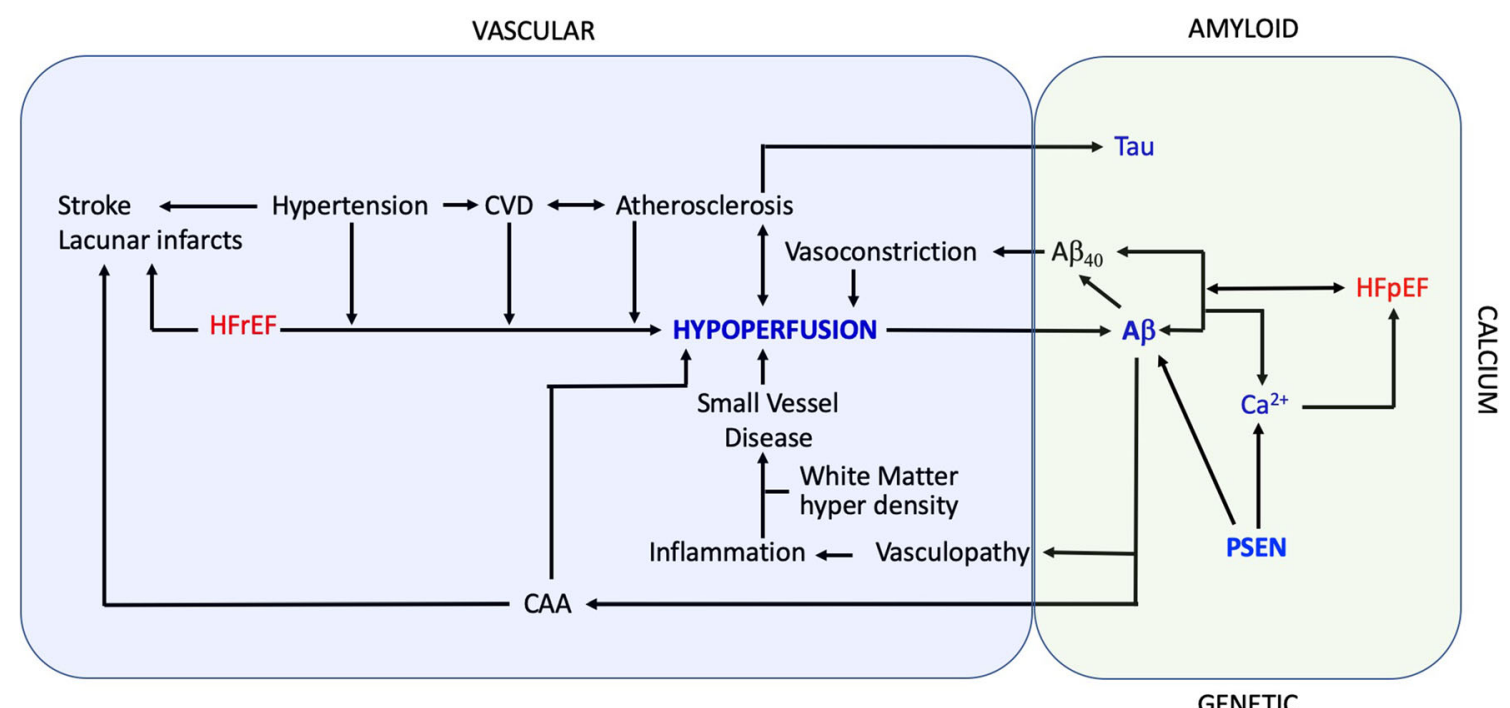

Fig. 1 Graphic abstract summarizing the currently known pathways for the vascular hypothesis (shaded in blue) on the left and the novel hypothesis for the common proteinopathy hypothesis of $\mathrm{HF}$ and $\mathrm{AD}$ (shaded in green) on the right. The two pathways are coexisting in the complex relationship between $\mathrm{HF}$ and $\mathrm{AD}$ 
$\mathrm{A} \beta$ is removed from the brain through the $\mathrm{BBB}$, the interstitial bulk flow clearance (glymphatic) system, or meningeal lymphatics [27, 28]. Substantial evidence exists highlighting the impairment of these drainage systems - in addition to the upregulation of $\beta$ secretase, BACE1 [29], and the action microRNA-124 [30-33] — in chronic cerebral hypoperfusion and $\mathrm{AD}$ with the subsequent accumulation of $\mathrm{A} \beta$ within the perivascular space $[28,59,85]$.

Amyloid- $\beta$ would in turn evoke oxidative imbalance with the accumulation of $A \beta$ in the mitochondria worsening mitochondrial dysfunction, ROS production, and overall oxidative imbalance as shown in mice models and human subjects with $\mathrm{AD}$ [24-26]. Worsening this vicious circle, the accumulation of $A \beta$ in the brain also exerts profound vascular effects due to its vasoconstrictive properties and ability to promote BBB disruption with a major impact in favoring the neurodegenerative processes. Moreover, the increased BBB permeability is also responsible for increased adherence and transmigration of monocytes from the periphery-to-CNS, which then differentiates into microglia promoting neuro-inflammation [86].

While previously thought of as a coincidental event, new evidence has emerged implicating immune mediators in disease progression [87]. Various cytokines and chemokines are released from an array of cells following an ischemic event [21]. Activation of the microglia has been regarded as particularly important, as these scavenger cells function both in the inflammatory cascade and the removal of $A \beta$ from the brain $[34,87]$. Under conditions of chronic low blood flow and glucose delivery, activated microglia were scarce in areas surrounding $A \beta$ plaques and exhibited impaired functioning [34]. Thus, the reduced capability for these microglia to effectively clear $A \beta$ confers an environment ideal for accumulation, aggregation, and further plaque formation.

\section{Cardiovascular Hemodynamics: HFrEF and HFpEF}

As an extension of the vascular hypothesis of dementia and $\mathrm{AD}$, reduced perfusion to the brain $[74,84,88,89]$ was considered also the predominant contributor to the reduced cognitive function in patients with HF. However, improved cognitive function from increased blood flow to the brain would be expected in all dementia, and atherosclerosis with reduced blood flow to the brain is present also in non-demented subjects.

While clinical studies have shown an association between dementia and HF, with HF patients incurring more than fourfold increase in cognitive impairment [90], further refinement of the characteristics of the patient's populations provided clues that perfusion per se might not be the primary pathogenic initiator of the cognitive dysfunction in all HF patients. A subgroup of patients within the prospective population-based Rotterdam Study included 3291 participants age 58 to 98 years in order to determine if cardiac function is associated with the risk of stroke and dementia. When echocardiographic signs of diastolic dysfunction (E/A ratio) were analyzed, it emerged that, in elderly people, free of clinical cardiac disease, dementia is associated with worse diastolic, but not systolic function. The latter was only related to clinical stroke [36]. Similarly, the study of the Swedish Heart Failure Registry and the Swedish Dementia Registry also failed to see a prevalent distribution of dementia and $\mathrm{AD}$ in subjects with $\mathrm{HF}$ with reduced ejection fraction (HFrEF) with striking overlapping distributions of dementia and $\mathrm{AD}$ within the HF with preserved ejection fraction (HFpEF) group of patients [35].

Those results seem to imply that preserved cardiac ejection fraction and, thus, preserved brain perfusion associates with the risk of dementia. Despite impaired LV diastolic function, LV end-diastolic volume (preload) is generally normal in HFpEF patients, though this comes at the expense of high filling pressure. Notwithstanding, the ability of LV to increase the stroke volume during stress or exercise is impaired owing to the inability of the myocardium to increase contractility (impaired contractile reserve) [37-44]. This phenomenon is further amplified by inadequate peripheral vasodilation and blunted heart rate response to exercise [37, 40, 43, 45-48] leading to organ hypoperfusion. Moreover, increased arterial stiffness combined with increases in LV end-systolic elastance give rise to exaggerated fluctuation in blood pressure resulting in abrupt transient decline of peripheral perfusion $[49,50]$ and pulsatile pressure transmitted to the brain microcirculation ("biomechanical hypothesis"). The increased central arterial stiffness and elevated central pulsatility have been associated with greater $A \beta$ accumulation in the brain of older subjects [51]. Furthermore, the increased arterial stiffness and central pressure exceeding the levels expected from aging and hypertension alone [91] in $\mathrm{HFpEF}$, in turn, promote cerebrovascular dysfunction, parenchymal injury of the brain, and BBB disruption.

These profound hemodynamic derangements are accompanied by anatomic (capillary rarefaction) and functional dysfunction (reduced endothelial nitric oxide bio-availability) of the microcirculation and cerebrovascular flow dysregulation which altogether concur to chronic brain hypoperfusion and hypoxia. Those changes together with key pathogenic factors in HFpEF - namely the pro-inflammatory state, coronary microcirculation dysfunction, and capillary rarefactioncomplicate the link between myocardial function and risk of dementia.

\section{A Transformative View of HF-AD Pathogenesis}

The close interaction between HFpEF and AD is not simply characterized by the abovementioned commonalities in risk factors and the independent association between $\mathrm{HF}$ and $\mathrm{AD}$ 
[10]. Similar genetic backgrounds and pathophysiology mechanisms have recently emerged and, in addition to the risk of $\mathrm{AD}$ in $\mathrm{HF}$ patients, known pathogenic clues of $\mathrm{AD}$ seem to participate in the pathogenesis of HF.

Recently described specific biological relationships between the two conditions, in fact, include (1) the presence of misfolded protein aggregates in the myocardium of patients with idiopathic dilated cardiomyopathy (iDCM) [4]; (2) common genetic variants in the same gene associated with earlyonset $\mathrm{AD}(P S E N)$ being also associated with iDCM [4, 12]; and (3) common biochemical components of the aggregates in $\mathrm{AD}$ and non-ischemic [6] and ischemic cardiomyopathies [92, 93]. Notably, (4) the same mechanism of toxicity attributed to the soluble PAO [94] now links the amyloid and calcium hypothesis of $\mathrm{AD}$ to the well-known calcium abnormalities that represented the traditional central pathogenesis in HF [4, 95-98] (an aspect not discussed in this review).

\section{HF a Novel Proteinopathy}

Accumulation of aggregates of misfolded proteins in the form of extracellular plaques and intracellular tangles was the first breakthrough in the identification of a new illness by Alois Alzheimer [99] and, for a long time, it remained pathogenically restricted to the specific form of dementia of $\mathrm{AD}$. The extension of the misfolding of proteins as a key pathogenic event to neurodegenerative diseases beyond dementia and $\mathrm{AD}$ represented the first step to the consequent discovery that misfolded protein can accumulate in any tissue/organ in degenerative diseases. Now more than 300 different illnesses are recognized as diseases of protein folding or proteinopathies [100].

Proteinopathy of the heart has been among the last to be included in the family. Protein aggregates were described in mice models of skeletal muscle diseases affecting the heart (desmin cardio/myopathy) [101], in human primary cardiomyopathies [4], and atrial fibrillation [54] raising confusion with the "classical" cardiac amyloidosis. While traditional cardiac amyloidosis presents prevalent extracellular aggregates, due to the extracardiac origin of the amyloid migrating to the heart, the discovery of intracellular amyloid aggregates due to their primary cardiac origin will present a new challenge for the definition and classification of cardiac amyloidosis, retracing the shift from the clinical (primary, secondary) to the biochemical (AAL, AAT) definition.

\section{Common Genetics}

The genetic fingerprint of AD was recently found to converge with iDCM. Mutations in the genes commonly associated with familial AD (FAD), namely presenilin-1 and -2 (PSEN1 and PSEN2), have been found to be associated with familial iDCM [12]. Even though iDCM and AD share a common genetic background, in both conditions less than $5 \%$ of the cases are inherited in a Mendelian autosomal dominant manner. The majority of cases, instead, occur sporadically in individuals without a clear Mendelian inherited profile. Our group identified genetic variants of PSEN1 and $P S E N 2$ in sporadic cased of iDCM, suggesting that genetic variants in PSEN may not only increase the risk of developing chronic degenerative diseases in the heart and brain as for the APOE4 gene in AD, but are directly associated with the disease [4]. Interestingly, our group found that not only genetic variants of the same PSEN gene, but also the same type of genetic variants associated with $\mathrm{AD}$ are associated with sporadic cases of iDCM and new variants (affecting the promoter region) not yet described in $\mathrm{AD}$ cases, appear in sporadic iDCM cases [4].

\section{Common Proteomic Profiles in AD and HF}

Although commonly referred as composed of aggregated proteolytic fragments (amyloid- $\beta$ ) of the amyloid precursor protein (APP) and hyperphosphorylated Tau protein, aggregates in the brain of $\mathrm{AD}$ contain a mixture of other molecules such as metal ions [52] as well as other proteins including molecular chaperones. Among the proteins composing the aggregates in $\mathrm{AD}$, the actin depolymerizing protein cofilin, known to precipitate in rod-like inclusions causing neuritis in $\mathrm{AD}$, was the first protein purified from the cardiac aggregates from iDCM human samples [6] and shown to be linked to the pathogenesis of dilated cardiomyopathy in a mouse model. Cofilin pathology also plays a role in a range of other neurodegenerative diseases (including corticobasal degeneration, William's syndrome, fragile $\mathrm{X}$ syndrome, spinal muscular atrophy) [53] as well as muscle diseases such as Nemaline myopathy [102] underlying the no one-to-one correspondence between aggregate's composition and disease, but rather a promiscuous nature of proteinopathies.

Whereas the first hallmark of $\mathrm{AD}$, the $\mathrm{A} \beta$ deposits, have not yet been formally documented in primary cardiomyopathy, both $A \beta_{40}$ and $A \beta_{42}$ are not blameless when it comes to affecting myocardial function. In an autoptic series, our group showed that $\mathrm{AD}$ patients, besides presenting $\mathrm{A} \beta$ plaques in the brain, showed deposits of $A \beta$ and PAOs in the heart as well, and the magnitude of cardiac aggregates was 10 -fold higher in comparison to non-AD age- and gender-matched subjects without brain's $A \beta$ deposits [7•]. By retrospective analysis, the clinical and transthoracic echocardiography data of $\mathrm{AD}$ patients and age and gender-matched non-AD subjects demonstrated higher likelihood to present with LV hypertrophy and HFpEF in AD patients than controls. The clinical results were endorsed in a subsequent study of $\mathrm{AD}$ and control patients supporting the significance of the study in a separate replication cohort [103]. Furthermore, the pathological findings were confirmed by another autoptic study, where cerebral 
amyloid angiopathy, a condition characterized by $\mathrm{A} \beta$ deposition in media and adventitia of the cerebral vessels, was strongly associated with $A \beta$ aggregates in the cardiomyocytes [104].

Whereas this evidence underlies common pathogenetic mechanisms in cardiomyopathy and $\mathrm{AD}$, whether the disease originates in one of the organs first or to both at the same time, and, in this case, why the disease presents with a prevalent cardiac phenotype in some patients and a brain disease in others is unknown. Those are difficult questions to answer due to the long asymptomatic latency in the development of the disease in humans and the challenging reproducibility of the human disease in the mouse models.

\section{AD and HF: a Systemic Disease}

Growing experimental evidences support the concept that AD, may extend beyond the brain as a result of the systemic accumulation of $A \beta$ and PAOs [105].

$\mathrm{A} \beta$ is produced by the $\beta$ - and $\gamma$-secretases sequential processing of the APP. This process gives rise to small amyloidogenic peptides of $40\left(\mathrm{~A} \beta_{40}\right)$ and $42\left(\mathrm{~A} \beta_{42}\right)$ amino acids that are able to aggregate to form soluble PAOs and insoluble $A \beta$ fibrils and plaques. In addition to brain cells, APP is processed by peripheral cells, including leukocytes, platelets, skeletal muscle, and cardiomyocytes; $A \beta$ and PAOs deposits have been described in the skin, subcutaneous tissue, skeletal muscle, guts, eyes, and now the heart [7•, 106-108] suggesting that tissues other than the brain may (even primarily) contribute to the diffuse accumulation of $A \beta$ within the new systemic view of Alzheimer's.

However, the level of $\mathrm{A} \beta$ are from 5 to 15 times higher in the cerebrospinal fluid (CSF) than in plasma $[109,110]$ possibly reflecting the less efficient cleavage of APP isoforms, higher amount of $\mathrm{A} \beta$-binding proteins (e.g., albumin and lipoproteins) [111] and number of cells (e.g., erythrocytes) [112] facilitating the clearance outside the brain. Failure to clear these peptides from the CNS promotes $\mathrm{AD}$ development or progression, and the failure to thwart the $A \beta$ and PAOs accumulation in the periphery may in turn cause or contribute to the amyloid-related systemic diseases hypothesis.

Furthermore, the pool of $A \beta$ has been reported to differ between the brain and the other body organs with a prevalent amyloidogenic prone and toxic $A \beta_{42}$ accumulating in the brain while $A \beta_{40}$ levels prevail outside the brain [113]. While there is still no clear explanation for the difference, the specific isoform distribution of APP has been documented with $\mathrm{APP}_{695}$, expressed predominantly in the brain, and $\mathrm{APP}_{751 / 770}$, mostly expressed by platelets and leucocytes [114], together with organ specific APP processing by the secretase enzymes $[113,115]$. However, the fluctuating levels of $A \beta_{40}$ and $A \beta_{42}$ in normal vs. pathological conditions, but also between individuals, make it difficult to draw definitive conclusions. The liver of normal individuals in fact present higher levels of $\mathrm{A} \beta$, perhaps reflecting the organ's clearance function [116], with liver function showing an inverse correlation with plasmatic levels of $A \beta$ [117]. Additionally, the dilution effect of the non-CNS districts and local biophysical factors contributing to $A \beta_{42}$ accumulation and oligomerization ( $\mathrm{pH}$, ionic strength, metals distribution) may contribute to the inhomogeneous distribution of $\mathrm{A} \beta$ and, consequently, the preferred organ deposition and disease development.

\section{AD and HF: a Metastatic Communication}

Whereas $A \beta$ production in the CNS and other organs suggests that $A \beta$ can independently accumulate outside the brain, $A \beta$ is released from the CNS for clearance and reduced clearance or increased production from other organs may seed back to the brain. The homeostasis of $\mathrm{A} \beta$ and PAOs in the CNS is, in fact, closely interwoven with that in the periphery [105] enabling the bi-directional transmission of the peptide.

In the brain, $A \beta$ and PAOs are cleared via phagocytosis by various cells (microglia, perivascular macrophages, neurons, and oligodendroglia), proteolysis by $\mathrm{A} \beta$-degrading enzymes (neprilysin, insulin-degrading enzyme, or metalloproteinases), but also efflux to peripheral circulation via transportation across BBB and blood-CSF barrier, interstitial fluid bulk flow, arachnoid villi, and glymphatic-lymphatic pathways [28]. Notably, more than $60 \%$ of $A \beta$ is cleared outside the brain [118-123]. Aging, cardiovascular, and AD risk factors may result in reduced $A \beta$ peripheral clearance, given decreased expression of $A \beta$ scavenger receptors, $A \beta$-degrading enzymes, impaired renal and liver function [55-58], and increased BBB permeability and leakage. The increase BBB permeability favors $A \beta$ efflux increasing circulating level of $A \beta$. This phenomenon may promote peripheral seeding of $A \beta$ and PAOs in highly perfused organs such as the heart.

As macromolecule, $A \beta$ crosses the BBB by active transport mediated by lipoprotein receptor-1 (LPR-1) and Pglycoprotein (P-gp) (from the CNS-to-periphery, $A \beta$ efflux), but also by receptor for advanced glycation end-product (RAGE) (from the periphery-to-CNS, $A \beta$ influx).

Recent evidences suggested that peripherally generated $A \beta$ and PAOs can enter the brain and contribute to $A \beta$ deposition in the case of BBB dysfunction. Peripheral inoculation of $A \beta$ containing brain extracts in fact induces cerebral $A \beta$ deposition, underpinning the potential role of peripherally generated $A \beta$ in the pathogenesis of $A D$ [59-63]. Similarly, peripherally generated $A \beta$, circulating inflammatory cytokines, and immune cells can travel back to the brain and contribute to $\mathrm{AD}$ pathogenesis, promoting $A \beta$ and PAOs aggregation and neuro-inflammation [64]. In a mouse model of AD (2xTg$\mathrm{AD})$, Grigorova et al. have shown that AD mice exhibited earlier onset of age-associated increase in aortic stiffness and LV hypertrophy as compared to age-matched non-transgenic 
counterparts, and that cardiac remodeling occurs only after the onset of brain amyloid accumulation [124].

Trafficking of molecules within and between organs has been recently revived by the growing evidence of the critical role of extracellular vesicles. In the brain, exosomes maintain important physiological functions, such as facilitating communication between neurons and glial cells [125], with impact on neuronal firing rate, signal transduction, and gene expression [126] and participate in $A \beta$ metabolism. Release of insulin-degrading enzymes from the exosomes would facilitate proteolysis of extracellular $A \beta$ [127], and exosomes facilitate phagocytosis and degradation by microglia cells [128, 129]. Exosomes containing $A \beta_{42}$ can originate directly from the cleavage of APP in lysosomes [65] or as a result of endocytosis of extracellular accumulated $A \beta_{42}$ in turn facilitating the transmission of $A \beta$ between cells in the same organ and between organs [66, 67].

In addition to shuttling $A \beta$ per se, exosomes mediate other molecular interaction between the brain and heart. Sun et al. described a new mechanism of brain damage originating in the heart [68•]. In a mouse model of myocardial infarction, high levels of MiR-1 (MicroRNA) were produced in the ischemic area and border zone. Once released in the bloodstream, MiR1 can reach the hippocampus where it would decrease TPPP/p25 protein expression and induce microtubule damage.

Altogether, those abnormalities provide yet another mechanism for the initiation or the progression of $\mathrm{AD}$ : the seeding of toxic PAO to and from sites outside the brain.

\section{Conclusions}

The relationship between $\mathrm{AD}$ and cardiovascular diseases, in particular heart failure (HF), is a new and intriguing field of research, at genetic/biomolecular and clinical levels. Statistical correlation between dementia, AD and HF is well proven and recognized. However, new emerging concepts compel the intriguing hypothesis of a common pathogenesis for $\mathrm{HF}$ and $\mathrm{AD}$ either from a systemic or metastatic origin. Notably, HFpEF could promote AD and vice versa, resulting in a reciprocal interaction amplifying their mutual pathogenic effects in two of the most vulnerable organs. The coexistence and reciprocal reinforcement of the brain and heart disease pose an alarming threat to population health with people living longer.

This picture might change in the near future. The current pandemic of coronavirus, first identified in January 2020 and almost swiftly declared Global Pandemic by March 11 by the World Health Organization, is rapidly affecting the most vulnerable population of chronically ill and senior citizens around the world with high mortality rates. Although this tragic sudden outbreak will sadly decimate the senior population (the most affected by degenerative diseases of the heart and brain). On the other hand, cardiovascular disease (CVD) emerged as a potential complication due to the high inflammatory load to the vasculature and heart in addition to questioning potential effects on the central nervous system. This will leave unpredictable long-term consequences on the epidemiology and patient stratification for chronic cardiovascular and neurodegenerative outcomes. Overall, this new epidemic might add a new population of patients at risk, further increasing the prevalence and, importantly, shifting the burden to an overall younger patient population.

\section{Compliance with Ethical Standards}

Conflict of Interest Gianlorenzo Daniele, Stephanie DiLucia, PierGiorgio Masci, and Federica del Monte declare that they have no conflict of interest.

Human and Animal Rights and Informed Consent This article does not contain any studies with human or animal subjects performed by any of the authors.

\section{References}

Papers of particular interest, published recently, have been highlighted as:

- Of importance

1 Go AS, Mozaffarian D, Roger VL, Benjamin EJ, Berry JD, Blaha MJ, et al. Heart disease and stroke statistics-2014 update: a report from the American Heart Association. Circulation. 2014;129(3): e28-e292.

2 Prince M PMaGM. World Alzheimer Report. 2013.

3 National Institute of Aging NIoH, Services USDoHaH. Alzheimer's disease progress report 2014-2015. https://www.nia. nih.gov/alzheimers/publication/2014-2015-alzheimers-diseaseprogress-report/introduction. 2015.

4 Gianni D, Li A, Tesco G, McKay KM, Moore J, Raygor K, et al. Protein aggregates and novel presenilin gene variants in idiopathic dilated cardiomyopathy. Circulation. 2010;121(10):1216-26.

5 del Monte F, Agnetti G. Protein post-translational modifications and misfolding: new concepts in heart failure. Proteomics Clin Appl. 2014;8(7-8):534-42.

6 Subramanian K, Gianni D, Balla C, Assenza GE, Joshi M, Semigran MJ, et al. Cofilin-2 phosphorylation and sequestration in myocardial aggregates: novel pathogenetic mechanisms for idiopathic dilated cardiomyopathy. J Am Coll Cardiol. 2015;65(12): 1199-214.

7. Troncone L, Luciani M, Coggins M, Wilker EH, Ho CY, Codispoti KE, et al. A $\beta$ amyloid pathology affects the hearts of patients with Alzheimer's disease: mind the heart. J Am Coll Cardiol. 2016;68(22):2395-407 This is the first study demonstrating the presence of $A \beta$ aggregates in the heart of patients with Alzheimer's disease and the clinical finding of diastolic dysfunction in Alzheimer's disease - the brain-to-heart link.

8 Pappolla MA, Bryant-Thomas TK, Herbert D, Pacheco J, Fabra Garcia M, Manjon M, et al. Mild hypercholesterolemia is an early risk factor for the development of Alzheimer amyloid pathology. Neurology. 2003;61(2):199-205. 
9 Razay G, Vreugdenhil A, Wilcock G. The metabolic syndrome and Alzheimer disease. Arch Neurol. 2007;64(1):93-6.

10 Qiu C, Winblad B, Marengoni A, Klarin I, Fastbom J, Fratiglioni L. Heart failure and risk of dementia and Alzheimer disease: a population-based cohort study. Arch Intern Med. 2006;166(9): 1003-8.

11 Gorza L, del Monte F. Protein unfolding in cardiomyopathies. Heart Fail Clin. 2005;1(2):237-50.

12 Li D, Parks SB, Kushner JD, Nauman D, Burgess D, Ludwigsen S, et al. Mutations of presenilin genes in dilated cardiomyopathy and heart failure. Am J Hum Genet. 2006;79(6):1030-9.

13 Willis MS, Patterson C. Proteotoxicity and cardiac dysfunctionAlzheimer's disease of the heart? N Engl J Med. 2013;368(5):45564.

14 Bernini F, Malferrari D, Pignataro M, Bortolotti CA, Di Rocco G, Lancellotti L, et al. Pre-amyloid oligomers budding:a metastatic mechanism of proteotoxicity. Sci Rep. 2016;6:35865.

15 Luciani M, Del Monte F. The more we learn, the less we know: a novel cardiac mechanism of brain damage. J Mol Cell Cardiol. 2019;128:158-9.

16 Cermakova P, Eriksdotter M, Lund LH, Winblad B, Religa P, Religa D. Heart failure and Alzheimer's disease. J Intern Med. 2015;277(4):406-25.

17 Benjamin EJ, Muntner P, Alonso A, Bittencourt MS, Callaway CW, Carson AP, et al. Heart disease and stroke statistics-2019 update: a report from the American Heart Association. Circulation. 2019;139(10):e56-e528.

18 de Toledo Ferraz Alves TC, Ferreira LK, Wajngarten M, Busatto GF. Cardiac disorders as risk factors for Alzheimer's disease. J Alzheimers Dis. 2010;20(3):749-63.

19 Cohen MB, Mather PJ. A review of the association between congestive heart failure and cognitive impairment. Am J Geriatr Cardiol. 2007;16(3):171-4.

20 Reitz C, Brickman AM, Luchsinger JA, Wu WE, Small SA, Tang MX. Frequency of subclinical heart disease in elderly persons with dementia. Am J Geriatr Cardiol. 2007;16(3):183-8.

21 Doyle KP, Simon RP, Stenzel-Poore MP. Mechanisms of ischemic brain damage. Neuropharmacology. 2008;55(3):310-8.

22 Love S, Miners JS. Cerebral Hypoperfusion and the energy deficit in Alzheimer's disease. Brain Pathol. 2016;26(5):607-17.

23 Zhu X, Smith MA, Honda K, Aliev G, Moreira PI, Nunomura A, et al. Vascular oxidative stress in Alzheimer disease. J Neurol Sci. 2007;257(1-2):240-6.

24 Matsuoka Y, Picciano M, La Francois J, Duff K. Fibrillar betaamyloid evokes oxidative damage in a transgenic mouse model of Alzheimer's disease. Neuroscience. 2001;104(3):609-13.

25 Zhao Y, Zhao B. Oxidative stress and the pathogenesis of Alzheimer's disease. Oxidative Med Cell Longev. 2013;2013: 316523.

26 de la Monte SM, Wands JR. Molecular indices of oxidative stress and mitochondrial dysfunction occur early and often progress with severity of Alzheimer's disease. J Alzheimers Dis. 2006;9(2):16781.

27 Iliff JJ, Wang M, Liao Y, Plogg BA, Peng W, Gundersen GA, et al. A paravascular pathway facilitates CSF flow through the brain parenchyma and the clearance of interstitial solutes, including amyloid beta. Sci Transl Med. 2012;4(147):147ra11.

28 Tarasoff-Conway JM, Carare RO, Osorio RS, Glodzik L, Butler T, Fieremans E, et al. Clearance systems in the brain-implications for Alzheimer disease. Nat Rev Neurol. 2015;11(8):457-70.

29 Sun X, He G, Qing H, Zhou W, Dobie F, Cai F, et al. Hypoxia facilitates Alzheimer's disease pathogenesis by up-regulating BACE1 gene expression. Proc Natl Acad Sci U S A. 2006;103(49):18727-32.
30 Bennett SA, Pappas BA, Stevens WD, Davidson CM, Fortin T, Chen J. Cleavage of amyloid precursor protein elicited by chronic cerebral hypoperfusion. Neurobiol Aging. 2000;21(2):207-14.

31 Cai Z, Liu Z, Xiao M, Wang C, Tian F. Chronic cerebral hypoperfusion promotes amyloid-beta pathogenesis via activating beta/gamma-secretases. Neurochem Res. 2017;42(12):3446-55.

32 Liu H, Xing A, Wang X, Liu G, Li L. Regulation of beta-amyloid level in the brain of rats with cerebrovascular hypoperfusion. Neurobiol Aging. 2012;33(4):826.e31-42.

33 Zhang X, Huang X, Fang C, Li Q, Cui J, Sun J, et al. miR-124 regulates the expression of BACE1 in the hippocampus under chronic cerebral hypoperfusion. Mol Neurobiol. 2017;54(4): 2498-506.

34 Bordeleau M, ElAli A, Rivest S. Severe chronic cerebral hypoperfusion induces microglial dysfunction leading to memory loss in APPswe/PS1 mice. Oncotarget. 2016;7(11):11864-80.

35 Cermakova P, Lund LH, Fereshtehnejad SM, Johnell K, Winblad B, Dahlstrom U, et al. Heart failure and dementia: survival in relation to types of heart failure and different dementia disorders. Eur J Heart Fail. 2015;17(6):612-9.

36 de Bruijn RF, Portegies ML, Leening MJ, Bos MJ, Hofman A, van der Lugt A, et al. Subclinical cardiac dysfunction increases the risk of stroke and dementia: the Rotterdam Study. Neurology. 2015;84(8):833-40.

37 Borlaug BA, Melenovsky V, Russell SD, Kessler K, Pacak K, Becker LC, et al. Impaired chronotropic and vasodilator reserves limit exercise capacity in patients with heart failure and a preserved ejection fraction. Circulation. 2006;114(20):2138-47.

38 Tan YT, Wenzelburger F, Lee E, Heatlie G, Leyva F, Patel K, et al. The pathophysiology of heart failure with normal ejection fraction: exercise echocardiography reveals complex abnormalities of both systolic and diastolic ventricular function involving torsion, untwist, and longitudinal motion. J Am Coll Cardiol. 2009;54(1): 36- 46.

39 Phan TT, Abozguia K, Nallur Shivu G, Mahadevan G, Ahmed I, Williams L, et al. Heart failure with preserved ejection fraction is characterized by dynamic impairment of active relaxation and contraction of the left ventricle on exercise and associated with myocardial energy deficiency. J Am Coll Cardiol. 2009;54(5):402-9.

40 Borlaug BA, Olson TP, Lam CS, Flood KS, Lerman A, Johnson $\mathrm{BD}$, et al. Global cardiovascular reserve dysfunction in heart failure with preserved ejection fraction. J Am Coll Cardiol. 2010;56(11):845-54.

41 Lee AP, Song JK, Yip GW, Zhang Q, Zhu TG, Li C, et al. Importance of dynamic dyssynchrony in the occurrence of hypertensive heart failure with normal ejection fraction. Eur Heart J. 2010;31(21):2642-9.

42 Shibata S, Hastings JL, Prasad A, Fu Q, Bhella PS, Pacini E, et al. Congestive heart failure with preserved ejection fraction is associated with severely impaired dynamic Starling mechanism. J Appl Physiol (1985). 2011;110(4):964-71.

43 Abudiab MM, Redfield MM, Melenovsky V, Olson TP, Kass DA, Johnson BD, et al. Cardiac output response to exercise in relation to metabolic demand in heart failure with preserved ejection fraction. Eur J Heart Fail. 2013;15(7):776-85.

44 Tan YT, Wenzelburger F, Lee E, Heatlie G, Frenneaux M, Sanderson JE. Abnormal left ventricular function occurs on exercise in well-treated hypertensive subjects with normal resting echocardiography. Heart. 2010;96(12):948-55.

45 Brubaker PH, Joo KC, Stewart KP, Fray B, Moore B, Kitzman DW. Chronotropic incompetence and its contribution to exercise intolerance in older heart failure patients. J Cardpulm Rehabil. 2006;26(2):86-9.

46 Maeder MT, Thompson BR, Brunner-La Rocca HP, Kaye DM. Hemodynamic basis of exercise limitation in patients with heart 
failure and normal ejection fraction. J Am Coll Cardiol. 2010;56(11):855-63.

47 Haykowsky MJ, Brubaker PH, John JM, Stewart KP, Morgan TM, Kitzman DW. Determinants of exercise intolerance in elderly heart failure patients with preserved ejection fraction. J Am Coll Cardiol. 2011;58(3):265-74

48 Phan TT, Shivu GN, Abozguia K, Davies C, Nassimizadeh M, Jimenez D, et al. Impaired heart rate recovery and chronotropic incompetence in patients with heart failure with preserved ejection fraction. Circ Heart Fail. 2010;3(1):29-34.

49 Schwartzenberg S, Redfield MM, From AM, Sorajja P, Nishimura RA, Borlaug BA. Effects of vasodilation in heart failure with preserved or reduced ejection fraction implications of distinct pathophysiologies on response to therapy. J Am Coll Cardiol. 2012;59(5):442-51.

50 Lam CS, Roger VL, Rodeheffer RJ, Bursi F, Borlaug BA, Ommen $\mathrm{SR}$, et al. Cardiac structure and ventricular-vascular function in persons with heart failure and preserved ejection fraction from Olmsted County, Minnesota. Circulation. 2007;115(15):1982-90.

51 Hughes TM, Wagenknecht LE, Craft S, Mintz A, Heiss G, Palta P, et al. Arterial stiffness and dementia pathology: Atherosclerosis Risk in Communities (ARIC)-PET Study. Neurology. 2018;90(14):e1248-e56.

52 Xiong F, Ge W, Ma C. Quantitative proteomics reveals distinct composition of amyloid plaques in Alzheimer's disease. Alzheimers Dement. 2019;15(3):429-40.

53 Maloney MT, Bamburg JR. Cofilin-mediated neurodegeneration in Alzheimer's disease and other amyloidopathies. Mol Neurobiol. 2007;35(1):21-44.

54 Podduturi V, Armstrong DR, Hitchcock MA, Roberts WC, Guileyardo JM. Isolated atrial amyloidosis and the importance of molecular classification. Proc (Bayl Univ Med Cent). 2013;26(4): 387-9.

55 Frenkel D, Wilkinson K, Zhao L, Hickman SE, Means TK, Puckett L, et al. Scaral deficiency impairs clearance of soluble amyloidbeta by mononuclear phagocytes and accelerates Alzheimer's-like disease progression. Nat Commun. 2013;4:2030.

56 Krabbe G, Halle A, Matyash V, Rinnenthal JL, Eom GD, Bernhardt U, et al. Functional impairment of microglia coincides with Beta-amyloid deposition in mice with Alzheimer-like pathology. PLoS One. 2013;8(4):e60921.

57 Zaghi J, Goldenson B, Inayathullah M, Lossinsky AS, Masoumi A, Avagyan H, et al. Alzheimer disease macrophages shuttle amyloid-beta from neurons to vessels, contributing to amyloid angiopathy. Acta Neuropathol. 2009;117(2):111-24.

58 Gu BJ, Huang X, Ou A, Rembach A, Fowler C, Avula PK, et al. Innate phagocytosis by peripheral blood monocytes is altered in Alzheimer's disease. Acta Neuropathol. 2016;132(3):377-89.

59 Bannai T, Mano T, Chen X, Ohtomo G, Ohtomo R, Tsuchida T, et al. Chronic cerebral hypoperfusion shifts the equilibrium of amyloid beta oligomers to aggregation-prone species with higher molecular weight. Sci Rep. 2019;9(1):2827.

60 Eisele YS, Obermuller U, Heilbronner G, Baumann F, Kaeser SA, Wolburg $\mathrm{H}$, et al. Peripherally applied $\mathrm{A} \beta$-containing inoculates induce cerebral $\beta$-amyloidosis. Science. 2010;330(6006):980-2.

61 Eisele YS, Fritschi SK, Hamaguchi T, Obermuller U, Fuger P, Skodras A, et al. Multiple factors contribute to the peripheral induction of cerebral $\beta$-amyloidosis. J Neurosci. 2014;34(31): 10264-73.

62 Ritchie DL, Adlard P, Peden AH, Lowrie S, Le Grice M, Burns K, et al. Amyloid-beta accumulation in the CNS in human growth hormone recipients in the UK. Acta Neuropathol. 2017;134(2): 221-40.

63 Jaunmuktane Z, Mead S, Ellis M, Wadsworth JD, Nicoll AJ, Kenny J, et al. Evidence for human transmission of amyloid-beta pathology and cerebral amyloid angiopathy. Nature. 2015;525(7568):247-50.

64 Moreno-Gonzalez I, Edwards Iii G, Salvadores N, Shahnawaz M, Diaz-Espinoza R, Soto C. Molecular interaction between type 2 diabetes and Alzheimer's disease through cross-seeding of protein misfolding. Mol Psychiatry. 2017;22(9):1327-34.

$65 \mathrm{Hu}$ X, Crick SL, Bu G, Frieden C, Pappu RV, Lee JM. Amyloid seeds formed by cellular uptake, concentration, and aggregation of the amyloid-beta peptide. Proc Natl Acad Sci U S A. 2009;106(48):20324-9.

66 Caporaso GL, Takei K, Gandy SE, Matteoli M, Mundigl O, Greengard $\mathrm{P}$, et al. Morphologic and biochemical analysis of the intracellular trafficking of the Alzheimer beta/A4 amyloid precursor protein. J Neurosci. 1994;14(5 Pt 2):3122-38.

67. Tam JH, Seah C, Pasternak SH. The amyloid precursor protein is rapidly transported from the Golgi apparatus to the lysosome and where it is processed into beta-amyloid. Mol Brain. 2014;7:54.

68 Sun LL, Duan MJ, Ma JC, Xu L, Mao M, Biddyut D, et al. Myocardial infarction-induced hippocampal microtubule damage by cardiac originating microRNA-1 in mice. J Mol Cell Cardiol. 2018;120:12-27 Findings from this study first demonstrated that damages to the heart can induce molecular abnormalities in the brain besides perfusion defects - the heart-to-brain link.

69 Cardiogenic dementia. Lancet 1977;1(8001):27-8.

70 Ames BN, Shigenaga MK, Hagen TM. Oxidants, antioxidants, and the degenerative diseases of aging. Proc Natl Acad Sci U S A. 1993;90(17):7915-22.

71 Moreira PI, Smith MA, Zhu X, Nunomura A, Castellani RJ, Perry G. Oxidative stress and neurodegeneration. Ann N Y Acad Sci. 2005;1043:545-52.

72 Gorelick PB, Scuteri A, Black SE, Decarli C, Greenberg SM, Iadecola $\mathrm{C}$, et al. Vascular contributions to cognitive impairment and dementia: a statement for healthcare professionals from the American Heart Association/American Stroke Association. Stroke. 2011;42(9):2672-713.

73 de la Torre JC. Cerebrovascular and cardiovascular pathology in Alzheimer's disease. Int Rev Neurobiol. 2009;84:35-48.

74 Roher AE, Debbins JP, Malek-Ahmadi M, Chen K, Pipe JG, Maze $\mathrm{S}$, et al. Cerebral blood flow in Alzheimer's disease. Vasc Health Risk Manag. 2012;8:599-611.

76 de la Torre JC. Vascular basis of Alzheimer's pathogenesis. Ann N Y Acad Sci. 2002;977:196-215.

75 Iadecola $C$. The pathobiology of vascular dementia. Neuron. 2013;80(4):844-66.

77 Jagust W. Untangling vascular dementia. Lancet. 2001;358(9299): 2097-8.

78 de la Torre JC. Alzheimer disease as a vascular disorder: nosological evidence. Stroke. 2002;33(4):1152-62.

79 de la Torre JC, Mussivand T. Can disturbed brain microcirculation cause Alzheimer's disease? Neurol Res. 1993;15(3):146-53.

80 Selkoe DJ, Hardy J. The amyloid hypothesis of Alzheimer's disease at 25 years. EMBO Mol Med. 2016;8(6):595-608.

81 Rius-Perez S, Tormos AM, Perez S, Talens-Visconti R. Vascular pathology: cause or effect in Alzheimer disease? Neurologia. 2018;33(2):112-20.

82 Vakharia K, Shallwani H, Beecher JS, Jowdy PK, Levy EI. 23 Endovascular treatment of acute stroke and occlusive cerebrovascular disease. In: Ellenbogen RG, Sekhar LN, Kitchen ND, da Silva HB, editors. Principles of Neurological Surgery (Fourth Edition). Philadelphia: Content Repository Only!; 2018, p. 34354.e4.

83 Cortes-Canteli M, Iadecola C. Alzheimer's disease and vascular aging: JACC focus seminar. J Am Coll Cardiol. 2020;75(8):942_ 51.

84 van de Haar HJ, Jansen JFA, van Osch MJP, van Buchem MA, Muller M, Wong SM, et al. Neurovascular unit impairment in early 
Alzheimer's disease measured with magnetic resonance imaging. Neurobiol Aging. 2016;45:190-6.

85 Liesz A. The vascular side of Alzheimer's disease. Science. 2019;365(6450):223-4.

86 Di Marco LY, Venneri A, Farkas E, Evans PC, Marzo A, Frangi AF. Vascular dysfunction in the pathogenesis of Alzheimer's disease-a review of endothelium-mediated mechanisms and ensuing vicious circles. Neurobiol Dis. 2015;82:593-606.

87 Heppner FL, Ransohoff RM, Becher B. Immune attack: the role of inflammation in Alzheimer disease. Nat Rev Neurosci. 2015;16(6): 358-72.

88 Wolters FJ, Zonneveld HI, Hofman A, van der Lugt A, Koudstaal PJ, Vernooij MW, et al. Cerebral perfusion and the risk of dementia: a population-based study. Circulation. 2017;136(8):719-28.

89 Duncombe J, Kitamura A, Hase Y, Ihara M, Kalaria RN, Horsburgh K. Chronic cerebral hypoperfusion: a key mechanism leading to vascular cognitive impairment and dementia. Closing the translational gap between rodent models and human vascular cognitive impairment and dementia. Clin Sci (Lond). 2017;131(19):2451-68.

90 Sauve MJ, Lewis WR, Blankenbiller M, Rickabaugh B, Pressler SJ. Cognitive impairments in chronic heart failure: a case controlled study. J Card Fail. 2009;15(1):1-10.

91 Reddy YNV, Andersen MJ, Obokata M, Koepp KE, Kane GC, Melenovsky V, et al. Arterial stiffening with exercise in patients with heart failure and preserved ejection fraction. J Am Coll Cardiol. 2017;70(2):136-48.

92 Nguyen KDD, Das A, He J, Toldo S, Abbate A, Salloum FN. Hydrogen sulfide attenuates ischemic heart failure by suppressing pro-apoptotic cofilin-2. Circulation. 2014;130:A16666.

93 Chau VHDT, Romeo F, Balan B, Cain C, Toldo S, Tang D, et al. Cardiac expression profiles of cofilin-2 and H2S-producing enzyme 3-mercaptopyruvate sulfurtransferase in patients with endstage ischemic cardiomyopathy. 2017;136:A16744.

94 Demuro A, Mina E, Kayed R, Milton SC, Parker I, Glabe CG. Calcium dysregulation and membrane disruption as a ubiquitous neurotoxic mechanism of soluble amyloid oligomers. J Biol Chem. 2005;280(17):17294-300.

95 Bers DM. Cardiac excitation-contraction coupling. Nature. 2002;415(6868):198-205.

96 Wen Y, Yang SH, Liu R, Perez EJ, Brun-Zinkernagel AM, Koulen $\mathrm{P}$, et al. Cdk5 is involved in NFT-like tauopathy induced by transient cerebral ischemia in female rats. Biochim Biophys Acta. 2007;1772(4):473-83.

97 Zile MR, Gaasch WH. Abnormal calcium homeostasis: one mechanism in diastolic heart failure. J Am Coll Cardiol. 2011;58(2): $155-7$.

98 Del Monte F, Hajjar RJ. Intracellular devastation in heart failure. Heart Fail Rev. 2008;13(2):151-62.

99 Alzheimer A. A new disease of the cortex. Allg Z Psych. 1907;64: $146-8$.

100 Chiti F, Dobson CM. Protein misfolding, functional amyloid, and human disease. Annu Rev Biochem. 2006;75:333-66.

101 Sanbe A, Osinska H, Saffitz JE, Glabe CG, Kayed R, Maloyan A, et al. Desmin-related cardiomyopathy in transgenic mice: a cardiac amyloidosis. Proc Natl Acad Sci U S A. 2004;101(27):10132-6.

102 Agrawal PB, Greenleaf RS, Tomczak KK, Lehtokari VL, Wallgren-Pettersson $\mathrm{C}$, Wallefeld $\mathrm{W}$, et al. Nemaline myopathy with minicores caused by mutation of the CFL2 gene encoding the skeletal muscle actin-binding protein, cofilin-2. Am J Hum Genet. 2007;80(1):162-7.

103 Sanna GD, Nusdeo G, Piras MR, Forteleoni A, Murru MR, Saba PS, et al. Cardiac abnormalities in Alzheimer disease: clinical relevance beyond pathophysiological rationale and instrumental findings? JACC Heart Fail. 2019;7(2):121-8.
104 Kramer LM, Brettschneider J, Lennerz JK, Walcher D, Fang L, Rosenbohm A, et al. Amyloid precursor protein-fragmentscontaining inclusions in cardiomyocytes with basophilic degeneration and its association with cerebral amyloid angiopathy and myocardial fibrosis. Sci Rep. 2018;8(1):16594.

105 Wang J, Gu BJ, Masters CL, Wang YJ. A systemic view of Alzheimer disease - insights from amyloid-beta metabolism beyond the brain. Nat Rev Neurol. 2017;13(10):612-23.

106 Kuo YM, Kokjohn TA, Watson MD, Woods AS, Cotter RJ, Sue LI, et al. Elevated abeta42 in skeletal muscle of Alzheimer disease patients suggests peripheral alterations of AbetaPP metabolism. Am J Pathol. 2000;156(3):797-805.

107 Joachim CL, Mori H, Selkoe DJ. Amyloid beta-protein deposition in tissues other than brain in Alzheimer's disease. Nature. 1989;341(6239):226-30.

108 Koronyo Y, Salumbides BC, Black KL, Koronyo-Hamaoui M. Alzheimer's disease in the retina: imaging retinal abeta plaques for early diagnosis and therapy assessment. Neurodegener Dis. 2012;10(1-4):285-93.

109 Toledo JB, Vanderstichele H, Figurski M, Aisen PS, Petersen RC, Weiner MW, et al. Factors affecting $A \beta$ plasma levels and their utility as biomarkers in ADNI. Acta Neuropathol. 2011;122(4): 401-13.

110 Mehta PD, Pirttila T, Patrick BA, Barshatzky M, Mehta SP. Amyloid beta protein 1-40 and 1-42 levels in matched cerebrospinal fluid and plasma from patients with Alzheimer disease. Neurosci Lett. 2001;304(1-2):102-6.

111 Biere AL, Ostaszewski B, Stimson ER, Hyman BT, Maggio JE, Selkoe DJ. Amyloid beta-peptide is transported on lipoproteins and albumin in human plasma. J Biol Chem. 1996;271(51):32916-22.

112 Kuo YM, Kokjohn TA, Kalback W, Luehrs D, Galasko DR, Chevallier N, et al. Amyloid-beta peptides interact with plasma proteins and erythrocytes: implications for their quantitation in plasma. Biochem Biophys Res Commun. 2000;268(3):750-6.

113 Roher AE, Esh CL, Kokjohn TA, Castano EM, Van Vickle GD, Kalback WM, et al. Amyloid beta peptides in human plasma and tissues and their significance for Alzheimer's disease. Alzheimers Dement. 2009;5(1):18-29.

114 Li QX, Fuller SJ, Beyreuther K, Masters CL. The amyloid precursor protein of Alzheimer disease in human brain and blood. $\mathrm{J}$ Leukoc Biol. 1999;66(4):567-74.

115 Yankner BA, Mesulam MM. Seminars in medicine of the Beth Israel Hospital, Boston. beta-amyloid and the pathogenesis of Alzheimer's disease. N Engl J Med. 1991;325(26):1849-57.

116 Sehgal N, Gupta A, Valli RK, Joshi SD, Mills JT, Hamel E, et al. Withania somnifera reverses Alzheimer's disease pathology by enhancing low-density lipoprotein receptor-related protein in liver. Proc Natl Acad Sci U S A. 2012;109(9):3510-5.

117 Maarouf CL, Walker JE, Sue LI, Dugger BN, Beach TG, Serrano GE. Impaired hepatic amyloid-beta degradation in Alzheimer's disease. PLoS One. 2018;13(9):e0203659.

118 Ghiso J, Calero M, Matsubara E, Governale S, Chuba J, Beavis R, et al. Alzheimer's soluble amyloid beta is a normal component of human urine. FEBS Lett. 1997;408(1):105-8.

119 Ghiso J, Shayo M, Calero M, Ng D, Tomidokoro Y, Gandy S, et al. Systemic catabolism of Alzheimer's A $\beta 40$ and A $\beta 42$. J Biol Chem. 2004;279(44):45897-908.

120 Velayudhan L, Poppe M, Archer N, Proitsi P, Brown RG, Lovestone $\mathrm{S}$. Risk of developing dementia in people with diabetes and mild cognitive impairment. Br J Psychiatry. 2010;196(1):3640.

121 Liu Z, Zhu H, Fang GG, Walsh K, Mwamburi M, Wolozin B, et al. Characterization of insulin degrading enzyme and other amyloidbeta degrading proteases in human serum: a role in Alzheimer's disease? J Alzheimers Dis. 2012;29(2):329-40. 
122 Bradshaw EM, Chibnik LB, Keenan BT, Ottoboni L, Raj T, Tang A, et al. CD33 Alzheimer's disease locus: altered monocyte function and amyloid biology. Nat Neurosci. 2013;16(7):848-50.

123 Kanekiyo T, Bu G. The low-density lipoprotein receptor-related protein 1 and amyloid-beta clearance in Alzheimer's disease. Front Aging Neurosci. 2014;6:93.

124 Grigorova Y, Camandola S, Petrashevskaya N, McPherson R, Rumian NL, Hagood M, et al. Increase in aortic stiffness and development of cardiac hypertrophy is associated with cognitive impairment IN 2XTG-AD mice. Alzheimers Dement. 2018:P3-01.

125 Fruhbeis C, Frohlich D, Kuo WP, Kramer-Albers EM. Extracellular vesicles as mediators of neuron-glia communication. Front Cell Neurosci. 2013;7:182.

126 Frohlich D, Kuo WP, Fruhbeis C, Sun JJ, Zehendner CM, Luhmann HJ, et al. Multifaceted effects of oligodendroglial exosomes on neurons: impact on neuronal firing rate, signal transduction and gene regulation. Philos Trans R Soc Lond Ser B Biol Sci. 2014;369(1652)

127 Bulloj A, Leal MC, Xu H, Castano EM, Morelli L. Insulindegrading enzyme sorting in exosomes: a secretory pathway for a key brain amyloid-beta degrading protease. J Alzheimers Dis. 2010;19(1):79-95.

128 Vella LJ, Hill AF, Cheng L. Focus on extracellular vesicles: exosomes and their role in protein trafficking and biomarker potential in Alzheimer's and Parkinson's disease. Int J Mol Sci. 2016;17(2):173.

129 Yuyama K, Sun H, Mitsutake S, Igarashi Y. Sphingolipidmodulated exosome secretion promotes clearance of amyloidbeta by microglia. J Biol Chem. 2012;287(14):10977-89.

Publisher's Note Springer Nature remains neutral with regard to jurisdictional claims in published maps and institutional affiliations. 